NASA/TM-1999-000000

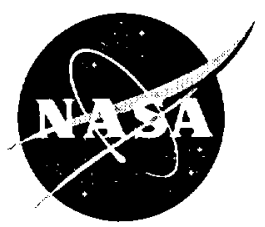

\title{
A Mixed Multi-Field Finite Element Formulation for Thermopiezoelectric Composite Shells
}

Ho-Jun Lee

Glenn Research Center, Cleveland, Ohio

Dimitris A. Saravanos

Ohio Aerospace Institute, Cleveland, Ohio

Prepared for the

Sixth Annual International Symposium on Smart Structures and Materials sponsored by the International Society for Optical Engineering Newport Beach, California, March 1-5, 1999

National Aeronautics and

Space Administration

Glenn Research Center 
Available from

NASA Center for Aerospace Information 7121 Standard Drive

Hanover, MD 21076

Price Code: $\mathrm{A} 03$
National Technical Information Service 5285 Port Royal Road Springfield, VA 22100 Price Code: A03 


\title{
A MIXED MULTI-FIELD FINITE ELEMENT FORMULATION FOR THERMOPIEZOELECTRIC COMPOSITE SHELLS
}

\author{
Ho-Jun Lee \\ National Aeronautics and Space Administration \\ Lewis Research Center \\ Cleveland, Ohio 44135 \\ and \\ Dimitris A. Saravanos* \\ Ohio Aerospace Institute \\ Brook Park, Ohio 44142
}

\begin{abstract}
Analytical formulations are presented which account for the coupled mechanical, electrical, and thermal response of piezoelectric composite shell structures. A new mixed multi-field laminate theory is developed which combines "single layer" assumptions for the displacements along with layerwise fields for the electric potential and temperature. This laminate theory is formulated using curvilinear coordinates and is based on the principles of linear thermopiezoelectricity. The mechanics have the inherent capability to explicitly model both the active and sensory responses of piezoelectric composite shells in thermal environments. Finite element equations are derived and implemented for an eight-noded shell element. Numerical studies are conducted to investigate both the sensory and active responses of piezoelectric composite shell structures subjected to thermal loads. Results for a cantilevered plate with an attached piezoelectric layer are compared with corresponding results from a commercial finite element code and a previously developed program. Additional studies are conducted on a cylindrical shell with an attached piezoelectric layer to demonstrate capabilities to achieve thermal shape control on curved piezoelectric structures.
\end{abstract}

\section{INTRODUCTION}

The potential performance advantages from utilizing smart structural components in advanced aerospace applications has lead to the extensive recent development of both analytical and experimental methods to characterize the behavior of these materials. Crawley (1994), Rao and Sunar (1994), and Rogers (1993) provide detailed overviews of smart structure technologies. Piezoelectric materials represent one of the more common materials currently being investigated for smart structures applications due to their inherent capability to be utilized as both actuators and sensors. Of practical interest are curved piezoelectric composite shells, since these configurations are most commonly used in various aerospace structural applications. In

*NASA Resident Research Associate at Lewis Research Center 
addition, most aerospace applications involve operations in changing thermal environments. Thus, in order to effectively and accurately characterize the response of smart structures with piezoelectric materials, the coupling effects from both the curvilinear geometry and thermopiezoelectricity must be accounted for in the analysis.

Numerous theories and models have been proposed to analyze piezoelectric composite beams, plates, shells, and solids. Saravanos and Heyliger (1998) provide a comprehensive review and classification of these analytical models, consequently only a brief review concerning piezoelectric shells is provided herein. Docmeci (1990) investigated the vibration of single layered piezoelectric shells. Lammering (1991) developed a Reissner-Mindlin shear deformable shell finite element, while Tzou and Gadre (1989) derived equations for thin piezoelectric shells based on the Kirchoff-Love hypothesis. Shell formulations and finite elements which explicitly account for the piezoelectric coupling have also been reported. Tzou and Ye (1996) modeled piezoelectric shells as a layerwise assembly of triangular elements. Heyliger et al. (1996) developed a discrete-layer laminated piezoelectric shell element. Saravanos (1997) implemented a mixed shear-layerwise theory for piezoelectric shells.

Limited research has been performed to assess the implications of thermal effects on piezoelectric composite shells. Tauchert (1992) constructed a piezoelectric plate theory for thermal behavior based on Kirchoff's assumptions in which the charge equation was not considered. Rao and Sunar (1993) developed a general finite element formulation for thermopiezoelectric plates. Tzou and Howard (1994) and Tzou and Bao (1995) postulated consistent, yet uncoupled, formulations for thin, shallow thermopiezoelectric shells based on classical laminate theory assumptions. Chandrashekhara and Kolli (1995) presented an uncoupled first-order shear finite element formulation for shallow piezoelectric composite shells under thermal loads. Tzou and Ye (1994) developed a three-dimensional finite element for thin thermopiezoelectric solids. Tzou and Bao (1997) included large-rotation geometric nonlinearity into their previously developed uncoupled models for thermal piezoelectric shells. Lee and Saravanos $(1996,1997)$ developed electromechanically coupled mechanics and finite elements for thermal laminated composite piezoelectric beams and plates, respectively, which use layerwise approximations for the displacements, electric potentials and temperature fields. Exact solutions for specific configurations of thermopiezoelectric plates and cylindrical shells have been reported by Dube et al. (1996a, 1996b), Xu and Noor (1996), Xu et al. (1997) and Choi et al. (1997).

Generally, most of the works described use approximate uncoupled models to account for the behavior of thermopiezoelectric laminated shells. However, neglecting the piezoelectric coupling that arises from the pyroelectric and thermal expansion coefficients can lead to substantial errors in predicting the structural response. Thus, this paper presents a coupled piezoelectric shell theory which incorporates thermal effects and has the capability to accurately predict the mechanical, electrical, and thermal response of thin and intermediately thick piezoelectric composite shells. The coupled behavior is captured at the material level through the thermopiezoelectric constitutive equations and the governing equations are formulated and 
solved in curvilinear coordinates. The mechanics incorporate different types of through-thethickness kinematic approximations for all field variables. First-order shear theory assumptions are used for the displacements, while discrete-layer theory approximations are implemented for the electric potential and temperature. The combination of mixed through-the-thickness approximations for the displacement, electric potential and temperature is a unique feature of the "mixed piezothermoelastic shell theory" (MPST) which enables the accurate analysis of thin and moderately thick piezoelectric shells.

\section{THERMOPIEZOELECTRIC LAMINATED SHELLS}

This section describes the analytical formulation for curvilinear thermopiezoelectric laminates with embedded sensory and active piezoelectric layers. The curvilinear laminate configuration is shown schematically in Figure 1. Each ply of the laminate remains parallel to a reference curvilinear surface $A_{0}$. An orthogonal curvilinear coordinate system $\bar{O}_{\xi \eta \zeta}$ is defined, such that the axes $\xi$ and $\eta$ lie on the curvilinear reference surface $A_{0}$, while the axis $\zeta$ remains straight and perpendicular to the layers of the laminate. A global Cartesian coordinate system $\mathrm{O}_{x y z}$ is used to define $A_{0}$, hence, a point $r=(x, y, z)$ on the curvilinear laminate is,

$$
r(\xi, \eta, \zeta)=r_{o}(\xi, \eta)+\zeta \hat{\zeta}
$$

where, $r_{0}=\left(x_{0}, y_{0}, z_{0}\right)$ are the Cartesian coordinates of the reference surface $A_{v}$, and $\hat{\zeta}$ indicates the unit vector perpendicular to the reference surface.

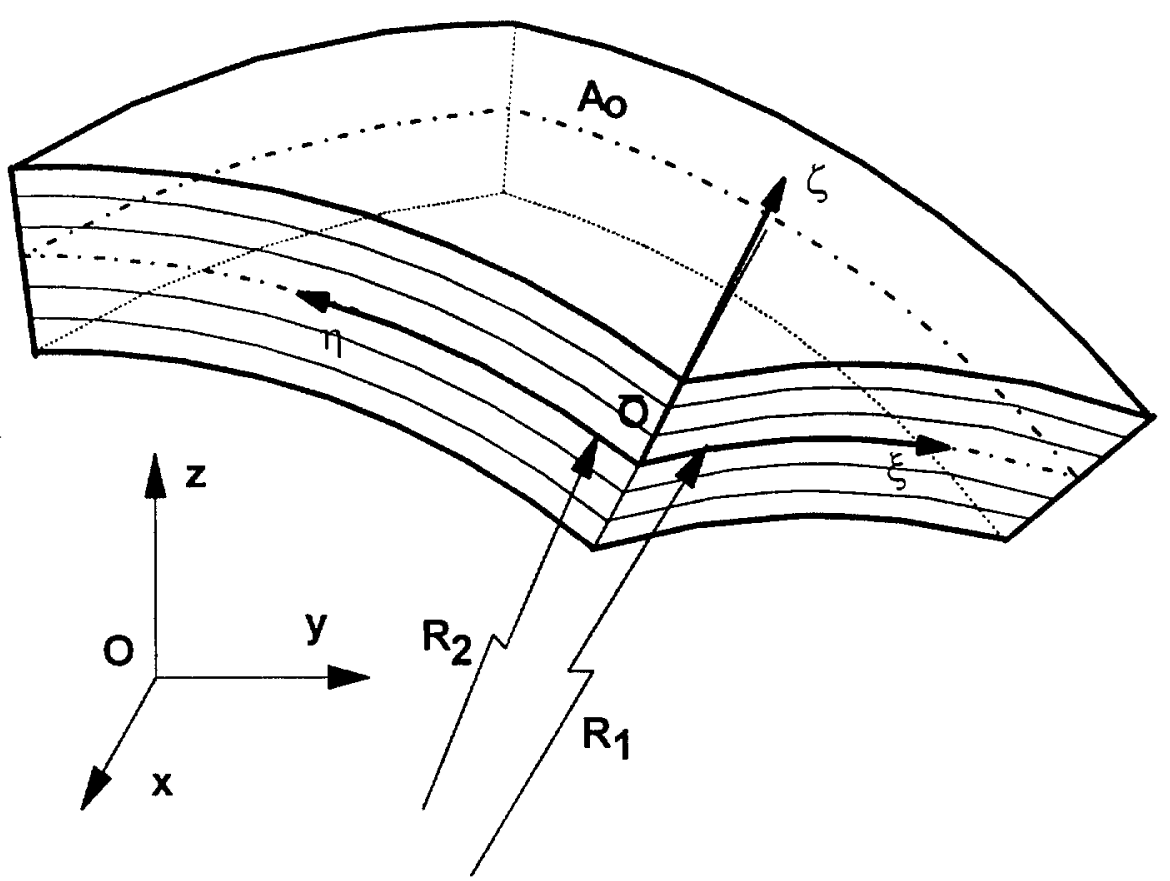

Figure 1: Curvilinear piezoelectric laminate and coordinate systems. 


\section{Governing Material Equations}

Each ply is assumed to consist of a linear piezoelectric material with properties defined in the orthogonal curvilinear system $\overline{\mathrm{O}}_{\xi \eta \xi}$, with constitutive equations of the following form,

$$
\begin{aligned}
\sigma_{i} & =C_{i j}^{E} S_{j}-e_{i k} E_{k}-\lambda_{i} \theta \\
D_{l} & =e_{l j} S_{j}+\varepsilon_{l k}^{S} E_{k}+p_{k} \theta
\end{aligned}
$$

where: $i, j=1, \ldots, 6$ and $k, l=1, \ldots, 3 ; \sigma_{i}$ and $S_{i}$ are the mechanical stresses and engineering strains in vectorial notation; $E_{k}$ is the electric field vector; $D_{l}$ is the electric displacement vector; $C_{i j}$ is the stiffness tensor; $\mathrm{e}_{i j}$ is the piezoelectric tensor; $\varepsilon_{i k}$ is the electric permittivity tensor of the material; $\lambda_{i}$ is the thermal expansion vector; $\theta=\Delta \mathrm{T}=\mathrm{T}-\mathrm{T}_{0}$ is the temperature difference from the thermally stress free reference temperature $T_{0}$; and $p_{k}$ is the pyroelectric vector. Superscripts $E$ and $S$ indicate constant electric field and strain conditions, respectively. The axes 1,2 , and 3 of the material are parallel to the curvilinear axes $\xi, \eta$, and $\zeta$, respectively. The materials are assumed to be monoclinic class 2 crystals with a diad axis parallel to the $z$ axis (Nye, 1964). The assumed material class is general enough, such that Eqs. (2) may encompass the behavior of offaxis homogenized piezoelectric plies, as well as the passive composite plies. The tensorial strain $\mathrm{S}_{\mathrm{ij}}$ and electric field components in a curvilinear coordinate system are related to the displacements and electric potential, respectively (Saravanos, 1997).

\section{Mixed Multi-Field Laminate Theory}

The proposed thermopiezoelectric shell theory combines linear displacement fields through the thickness of the laminate for the displacements $u$ and $v$ (along the $\xi$ and $\eta$ axes respectively) with layerwise electric potential and temperature fields through the laminate, consisting of $\mathrm{N}$ discrete continuous segments (see Figure 2). Previous works by Lee and Saravanos $(1996,1997)$ on layerwise theories for thermal piezoelectric beams and plates have demonstrated the advantages and necessity of layerwise approaches for capturing the complex electric fields and interactions which are present in piezoelectric actuators and sensors. Consequently, the present mixed piezothermoelastic shell theory (MPST) will entail the capability to (1) accurately and efficiently model thin and moderately thick laminated piezoelectric shells with arbitrary laminations and electric configurations, (2) capture the through-the-thickness electric heterogeneity induced by the embedded piezoelectric sensors and actuators, and (3) represent the changing thermal gradients through the laminate plies.

The discrete-layer kinematic assumption effectively subdivides the laminate into $\mathrm{N}-1$ sublaminates (or discrete-layers). A continuous linear electric potential and temperature variation is assumed in each sublaminate, such that $\mathrm{C}_{0}$ continuity results through-the-thickness of the laminate (see Figure 2). In this formulation, the subdivision can be arbitrarily altered according to the configuration of the piezoelectric layers or the desired level of approximation. Thus, the resulting "zig-zag" shape of the approximation can be a-priori controlled to vary the detail of approximation from a single-layer to a finely graded field. The various field variables are approximated by the following form, 


$$
\begin{aligned}
u(\xi, \eta, \zeta, t) & =u^{o}(\xi, \eta, t)+\zeta \beta_{\xi}(\xi, \eta, t) \\
v(\xi, \eta, \zeta, t) & =v^{o}(\xi, \eta, t)+\zeta \beta_{\eta}(\xi, \eta, t) \\
w(\xi, \eta, \zeta, t) & =w^{o}(\xi, \eta, t) \\
\phi(\xi, \eta, \zeta, t) & =\sum_{j=1}^{N} \phi^{j}(\xi, \eta, t) \Psi^{j}(\zeta) \\
\theta(\xi, \eta, \zeta, t) & =\sum_{j=1}^{N} \theta^{\prime}(\xi, \eta, t) \Psi^{j}(\zeta)
\end{aligned}
$$

where $\mathrm{u}^{0}, \mathrm{v}^{0}, \mathrm{w}^{0}$ are displacements along the $\xi, \eta$ and $\zeta$ axes, respectively, on the reference surface $A_{0}$; superscript $j$ indicates the points $\zeta^{j}$ at the beginning and end of each discrete layer; $\phi^{j}$ and $\theta^{j}$ are the electric potential and temperature at each point $\zeta^{j}$, respectively (see Figure 2 ); $\Psi^{\mathrm{j}}(\mathrm{z}$ ) are interpolation functions; and $\beta_{\xi}$ and $\beta_{\eta}$ are the rotation angles defined as,

$$
\beta_{\xi}=-\frac{w_{. \xi}^{o}}{g_{11}^{o}}+\frac{u^{o}}{R_{1}}, \quad \beta_{\eta}=-\frac{w_{. \eta}^{o}}{g_{22}^{o}}+\frac{v^{o}}{R_{2}}
$$

where $R_{i}$ are the local radii of curvature (Figure 1). Linear interpolation functions $\Psi(z)$ are considered in this paper.

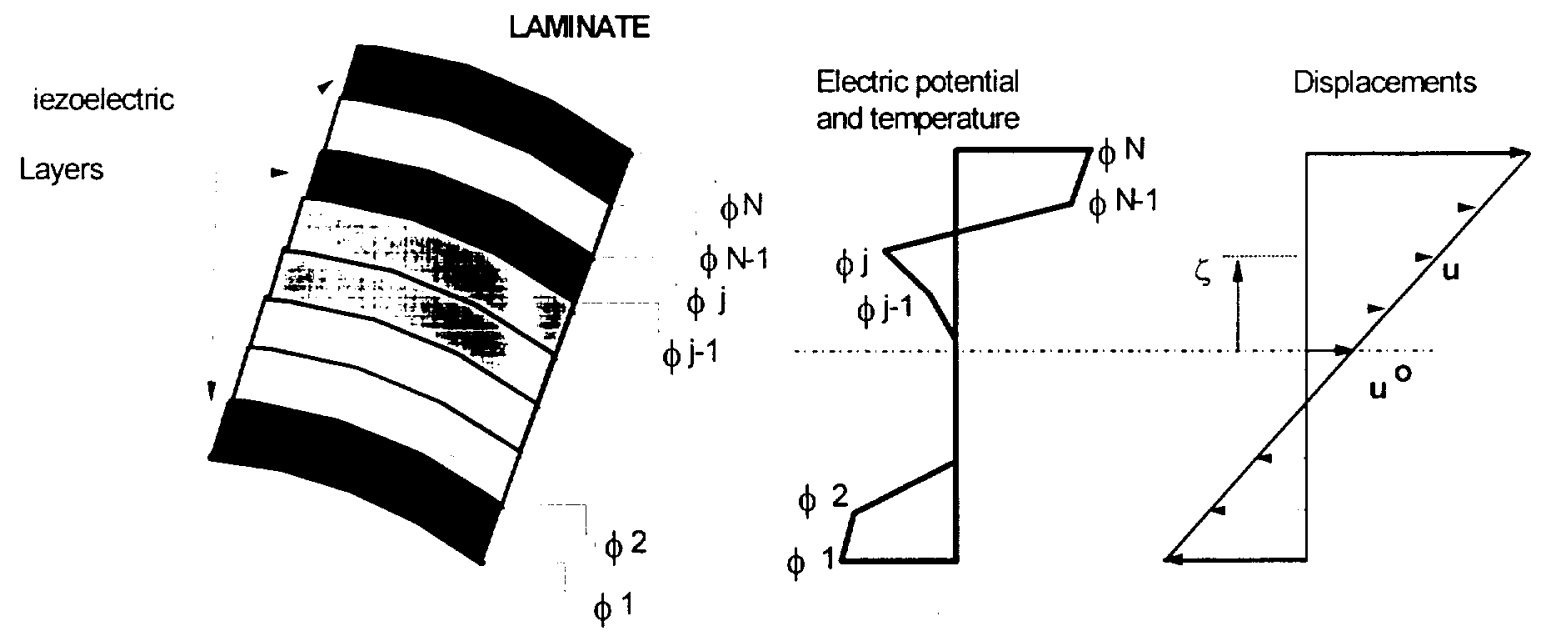

(a) Smart laminate

(b) Piezoelectric shell laminate theory assumptions

Figure 2: Typical piezoelectric laminate configuration.

(a) Concept; (b) Assumed through-the-thickness fields. 
The Love's assumption for shallow shells is further implemented, i.e. the local radii of the shell are substantially higher than the thickness $\left(h / R_{i}<1\right)$, yielding $\left(1+\zeta / R_{i} \approx 1\right)$. In the context of Eqs. (3), the engineering strains become

$$
\begin{aligned}
S_{i}(\xi, \eta, \zeta, t) & =S_{i}^{o}(\xi, \eta, t)+\zeta k_{i}(\xi, \eta, t) \quad i=1,2,6 \\
S_{3}(\xi, \eta, \zeta, t) & =0 \\
S_{i}(\xi, \eta, \zeta, t) & =S_{i}^{o}(\xi, \eta, l) \quad i=4,5
\end{aligned}
$$

where $\mathrm{S}^{\circ}$ and $\mathrm{k}$ are the strain and curvatures at the reference surface, defined as follows:

$$
\begin{gathered}
S_{1}^{o}=\frac{1}{g_{11}^{o}}\left(u_{, \xi}^{o}+\frac{g_{11, \eta}^{o}}{g_{22}^{o}} v^{o}\right)+\frac{w^{o}}{R_{1}}, \quad S_{2}^{o}=\frac{1}{g_{22}^{o}}\left(v_{, \eta}^{o}+\frac{g_{22, \xi}^{o}}{g_{11}^{o}} u^{o}\right)+\frac{w^{o}}{R_{2}} \\
S_{6}^{o}=\frac{1}{g_{11}^{o}}\left(v_{, \xi}^{o}-\frac{g_{11, \eta}^{o}}{g_{22}^{o}} u^{o}\right)+\frac{1}{g_{22}^{o}}\left(u_{, \eta}^{o}-\frac{\left.g_{22, \xi}^{o} v^{o}\right)}{g_{11}^{o}}\right. \\
S_{4}^{o}=\beta_{\eta}+\frac{w_{, \eta}^{o}}{g_{22}^{o}}-\frac{v^{o}}{R_{2}}, \quad S_{5}^{o}=\beta_{\xi}+\frac{w_{, \xi}^{o}}{g_{11}^{o}}-\frac{u^{o}}{R_{1}} \\
k_{1}=\frac{1}{g_{11}^{o}}\left(\beta_{\xi, \xi}+\frac{g_{11, \eta}^{o}}{g_{22}^{o}} \beta_{\eta}\right), \quad k_{2}=\frac{1}{g_{22}^{o}}\left(\beta_{\eta, \eta}+\frac{g_{22, \xi}^{o}}{g_{11}^{o}} \beta_{\xi}\right) \\
k_{6}=\frac{1}{g_{11}^{o}}\left(\beta_{\eta, \xi}-\frac{g_{11, \eta}^{o}}{g_{22}^{o}} \beta_{\xi}\right)+\frac{1}{g_{22}^{o}}\left(\beta_{\xi, \eta}-\frac{g_{22, \xi}^{o}}{g_{11}^{o}} \beta_{\eta}\right)
\end{gathered}
$$

where $\mathrm{R}_{i}$ are the local radii of curvature, and $\mathrm{g}_{11}{ }_{11}, \mathrm{~g}_{22}^{\mathrm{o}}$ are the components of the metric tensor on the surface $A_{0}(\zeta=0)$ defined as $\quad g_{11}^{o}=\sqrt{x_{o, \xi}^{2}+y_{o, \xi}^{2}+z_{o, \xi}^{2}}$ and $g_{22}^{o}=\sqrt{x_{o, \eta}^{2}+y_{o, \eta}^{2}+z_{o, \eta}^{2}}$.

The electric field vector also becomes,

$$
\begin{aligned}
& E_{i}(\xi, \eta, \zeta, t)=\sum_{j=1}^{N} E_{i}^{\prime}(\xi, \eta, t) \Psi^{j}(\zeta) \quad i=1,2 \\
& E_{3}(\xi, \eta, \zeta, t)=\sum_{j=1}^{N} E_{3}^{\prime}(\xi, \eta, t) \Psi_{, \zeta}^{j}(\zeta)
\end{aligned}
$$

where $\left\{E^{i}\right\}$ is the generalized electric field vector defined as: 


$$
E_{1}^{j}=-\frac{\Phi_{. \xi}^{j}}{g_{11}^{o}} \quad E_{2}^{j}=-\frac{\Phi_{, \eta}^{j}}{g_{22}^{o}} \quad E_{3}^{j}=-\Phi^{j}
$$

\section{Equations of Motion}

The variational form of the equations of motion in the orthogonal curvilinear system is,

$$
\int_{V}\{-\delta H(S, E)-\delta T\}|J| d \xi d \eta d \zeta+\int_{\Gamma_{S}} \delta u_{i}^{T_{\tau_{i}}}+\int_{\Gamma_{l}} \delta \phi \bar{D} d S=0
$$

where $\delta \mathrm{H}$ is the variation of the electric enthalphy and $\delta \mathrm{T}$ the variation of the kinetic energy, defined as,

$$
\begin{aligned}
\delta H & =\delta S_{i} \sigma_{i}-\delta E_{k} D_{k}=\delta S_{i} C_{i j} S_{j}-\delta S_{i} e_{l l} E_{l}-\delta S_{i} \lambda_{i} \theta-\delta E_{k} e_{k j} S_{j}-\delta E_{k} \varepsilon_{k l} E_{l}-\delta E_{k} p_{k} \theta \\
\delta T & =-\delta u_{i} \rho_{i} \dot{u}_{i}
\end{aligned}
$$

where $\bar{\tau}$ and $\bar{D}$ are the surface tractions and electric displacement acting on surfaces $\Gamma_{\mathrm{S}}$ and $\Gamma_{\mathrm{D}}$, respectively

$$
\bar{\tau}_{i}=\sigma_{i j} \hat{n}_{j}, \quad \bar{D}=D \hat{n}_{j} \quad i, j=1, \ldots, 3
$$

$[\mathrm{J}]$ is the Jacobian matrix of the transformation between the global cartesian and curvilinear system. For the curvilinear system $\overline{\mathrm{O}}_{\xi \eta \zeta}$ the determinant of the Jacobian takes the form:

$$
|J|=\left|\frac{\partial(x, y, z)}{\partial(\xi, \eta, \zeta)}\right|=g_{11}^{o} g_{22}^{o}\left(1+\zeta / R_{1}\right)\left(1+\zeta / R_{2}\right) \approx g_{1}^{o} g_{22}^{o}
$$

It is now possible to rearrange the variational statement and separate the through-the-thickness integration, as follows:

$$
\int_{A_{\iota}}-\left(\delta H_{L}(S, E)-\delta T_{L}\right) d \xi d \eta+\oint_{\Gamma}\left(\delta u_{i}{ }^{T} \bar{\tau}_{i}+\delta \phi \bar{D}\right) d \Gamma=0
$$

where $\mathrm{A}_{\mathrm{o}}$ is the curvilinear reference surface, $\bar{\tau}$ and $\bar{D}$ are the surface tractions and electric displacement on the boundary surface $\Gamma ; \delta \mathrm{H}_{\mathrm{L}}$ and $\delta \mathrm{T}_{\mathrm{L}}$ are the variations of the electric enthalpy and kinetic energy of the laminate, defined as

$$
<\delta H_{L}, \delta T_{L}>=\int_{0}^{h}<\delta H, \delta T>g_{11}^{o} g_{22}^{o} d \zeta
$$


and $\mathrm{h}$ is the laminate thickness. By combining Eqs. (11) and (15) and integrating through-thethickness, the variation of the electric enthalpy of the piezoelectric laminate is obtained as a quadratic expression of the generalized strain, electric field, and the generalized laminate matrices,

$$
\begin{aligned}
\delta H_{L}= & \delta S_{i}^{o} A_{i j} S_{j}^{o}+\delta S_{i}^{o} B_{i j} k_{j}+\delta k_{j} B_{j l} S_{i}^{o}+\delta k_{i} D_{i j} k_{j}- \\
& -\sum_{m=1}^{N}\left(\delta S_{i}^{o} \bar{E}_{i k}^{m} E_{k}^{m}+\delta E_{k}^{m} \bar{E}_{k i}^{m} S_{i}^{o}+\delta k_{j} \hat{E}_{j}^{m} E_{3}^{m}+\delta E_{3}^{m} \hat{E}_{j}^{m} k_{j}\right)-\sum_{m=1}^{N} \sum_{n=1}^{N} \delta E_{k}^{m} G_{k l}^{m n} E_{l}^{m} \\
& -\sum_{m=1}^{N}\left(\delta S_{i}^{o} \bar{\Lambda}_{i}^{m} \theta^{m}+\delta \theta^{m} \bar{\Lambda}_{i}^{m} S_{i}^{o}+\delta k_{j} \hat{\Lambda}_{j}^{m} \theta^{m}+\delta \theta^{m} \hat{\Lambda}_{j}^{m} k_{j}\right)-\sum_{m=1}^{N} \sum_{n=1}^{N} \delta E_{k}^{m} P_{k}^{m n} \theta^{m}
\end{aligned}
$$

In the above equation, [A], [B], and [D] are the stiffness matrices; [ $\left.\mathrm{E}^{\mathrm{m}}\right]$ overbar and overhat are the piezoelectric matrices; and $\left[\mathrm{G}^{\mathrm{mn}}\right]$ are the matrices of electric permittivity of the curvilinear laminate described by Saravanos (1997).

The generalized thermal matrices are new, and include the thermal expansion matrices $\left[\Lambda^{\prime \prime \prime}\right]$ overbar and overhat,

$$
<\bar{\Lambda}_{i}^{m}, \hat{\Lambda}_{i}^{m}>=g_{1 \mid}^{o} g_{22}^{o} \sum_{l=1}^{L} \int_{\zeta_{l}}^{\zeta_{\uparrow+1}} \lambda_{i} \Psi^{m}(\zeta)<1, \zeta>d \zeta, \quad i=1,2
$$

and the pyroelectric laminate matrices $\left[\mathrm{P}^{\mathrm{mn}}\right]$,

$$
\begin{aligned}
& P_{i}^{m n}=g_{1 !}^{o} g_{22}^{o} \sum_{l=1}^{L} \int_{\zeta_{l}}^{\zeta_{1+1}} p_{k} \Psi^{m}(\zeta) \Psi^{n}(\zeta) d \zeta, \quad k=1.2 \\
& P_{3}^{m n}=g_{1 !}^{o} g_{22}^{o} \sum_{l=1}^{L} \int_{\zeta_{l}}^{\zeta_{l+1}} p_{3} \Psi_{. \zeta}^{m}(\zeta) \Psi^{n}(\zeta) d \zeta
\end{aligned}
$$

where $\mathrm{L}$ is the number of plies in the laminate.

The kinetic energy of the laminate takes the form,

$$
\delta T_{L}=\delta u_{i}^{o} \rho_{i}^{A} \dot{u}_{i}^{o}+\delta u_{j}^{o} \rho_{j}^{B} \dot{\beta}_{j}+\delta \beta_{j} \rho_{j}^{B} \dot{u}_{j}+\delta \beta_{j} \rho_{j}^{D} \dot{\beta}_{J}, \quad i=1, \ldots, 3, j=1,2
$$

where $u_{i}^{o}=\left\{u^{\circ}, v^{o}, w^{0}\right\}$ and $\beta_{1}=\left\{\beta_{\xi}, \beta_{\eta}\right\} ; \rho^{A}, \rho^{B}, \rho^{D}$ are the generalized densities, expressing the mass, mass coupling and rotational inertia per unit area of the laminate (Saravanos, 1997).

\section{Finite Element Formulation}

The previous formulation of the governing equations in the orthogonal curvilinear system and the generalized variational statement in Eq. (11) enables the development of structural solutions by using approximations for the generalized multi-field state variables (displacements, rotation 
angles, electric potential and temperature) of the following type,

$$
\begin{array}{ll}
u_{j}^{o}(\xi, \eta, t)=\sum_{i=1}^{M} u_{j}^{o i}(t) N^{i}(\xi, \eta), & j=1, \ldots, 3 \\
\beta_{j}(\xi, \eta, t)=\sum_{i=1}^{M} \beta_{j}^{j}(t) N^{i}(\xi, \eta), & j=1,2 \\
\phi^{m}(\xi, \eta, t)=\sum_{i=1}^{M} \phi^{m i}(t) N^{i}(\xi, \eta), & m=1, \ldots, N \\
\theta^{m}(\xi, \eta, t)=\sum_{i=1}^{M} \theta^{m i}(t) N^{i}(\xi, \eta), & m=1, \ldots, N
\end{array}
$$

where superscript $\mathrm{i}$ indicates the reference surface displacement, rotation angle and generalized electric potential components corresponding to the i-th in-plane interpolation function $\mathrm{N}^{\mathrm{i}}(\xi, \eta)$. Implementation of local interpolation functions in Eqs. (19) results in the finite element based solutions. Combining Eqs. (6), (7), (9), and (20) results in the strain, electric field and temperature interpolation matrices. Substituting into the variational equations of motion Eqs. (14), and collecting the coefficients as mandated by Eqs. (16) and (19), the governing dynamic equations of the structure are expressed in the discrete matrix form,

$$
\left[\begin{array}{cc}
{\left[M_{u t u}\right]} & 0 \\
0 & 0
\end{array}\right]\left\{\begin{array}{c}
\{\ddot{u}\} \\
\left\{\ddot{\phi}^{F}\right\}
\end{array}\right\}+\left[\begin{array}{cc}
{\left[K_{u u l}\right]} & {\left[K_{u \phi}^{F F}\right]} \\
{\left[K_{\phi u}^{F F}\right]} & {\left[K_{\phi \phi}^{F F}\right]}
\end{array}\right]\left\{\begin{array}{c}
\{u\} \\
\left\{\phi^{F}\right\}
\end{array}\right\}=\left\{\begin{array}{c}
\{F(t)\}-\left[K_{u \phi}^{F A}\right]\left\{\phi^{A}\right\}-\left[K_{u \theta}\right]\{\theta\} \\
\left\{Q^{F}(t)\right\}-\left[K_{\phi \phi}^{F A}\right]\left\{\phi^{A}\right\}-\left[K_{\phi \theta}\right]\{\theta\}
\end{array}\right\}
$$

Submatrices $\mathrm{K}_{\mathrm{u}}, \mathrm{K}_{\mathrm{u \phi}}$ and $\mathrm{K}_{\phi \phi}$ indicate the elastic, piezoelectric and permittivity matrices; $\mathrm{K}_{\mathrm{u} \theta}$ and $\mathrm{K}_{\phi \varphi}$ are the thermal expansion and pyroelectric matrices of the structure; and $\mathrm{M}_{\mathrm{uu}}$ is the mass matrix. Superscripts F and A indicate the partitioned submatrices in accordance with the sensory (free) and active (applied) electric potential components, respectively, as explained previously (Lee and Saravanos, 1997). Thus, the left-hand side includes the unknown electromechanical response of the structure $\left\{u, \phi^{F}\right\}$, i.e. the resultant displacements and voltage at the sensors. The right-hand includes the excitation of the structure in terms of mechanical loads, applied voltages $\phi^{\mathrm{A}}$ on the actuators, applied temperature loads and electric charge at the sensors $\mathrm{Q}^{\mathrm{F}}(\mathrm{t})$.

Based on the above formulation, an eight-noded $(M=8)$ finite element was developed with biquadratic shape functions of the serendipity family. Reduced integration was applied selectively on the calculation of shear elastic and piezoelectric stiffness terms, as this has been found to improve the accuracy of the numerical predictions. These discrete equations can be easily condensated into the following independent equations for the sensory electric potentials,

$$
\left\{\phi^{F}\right\}=\left[K_{\phi \phi}^{F F}\right]^{-1}\left(\left[K_{\phi \phi}^{F A}\right]\left\{\phi^{A}\right\}+\left[K_{\phi \theta}\right]\{\theta\}-\left[K_{\phi u}^{F F}\right]\{u\}-\left\{Q^{F}(t)\right\}\right)
$$

and the structural displacements, 


$$
\begin{gathered}
{\left[M_{u u}\right]\{\ddot{u}\}+\left(\left[K_{u u}\right]-\left[K_{u \phi}^{F F}\right]\left[K_{\phi \phi}^{F F}\right]^{-1}\left[K_{\phi u}^{F F}\right]\right)\{u\}=} \\
\{F(t)\}-\left(\left[K_{u \phi}^{F F}\right]\left[K_{\phi \phi}^{F F}\right]^{-1}\left[K_{\phi \phi}^{F A}\right]+\left[K_{u \phi}^{F A}\right]\right)\left\{\phi^{A}\right\}+ \\
{\left[K_{u \phi}^{F F}\right]\left[K_{\phi \phi}^{F F}\right]^{-1}\left\{Q^{F}(t)\right\}-\left(\left[K_{u \phi}^{F F}\right]\left[K_{\phi \phi}^{F F}\right]^{-1}\left[K_{\phi \theta}\right]+\left[K_{u \theta}\right]\right)\{\theta\}}
\end{gathered}
$$

\section{NUMERICAL RESULTS AND DISCUSSION}

Evaluations of the developed mechanics and applications to various composite structures with piezoelectric actuators and sensors are presented in this section. In order to represent the location of the piezoelectric layers, the standard laminate notation is expanded, such that piezoelectric layers are indicated by the letter $\mathrm{p}$. The properties of both the piezoelectric and composite material are listed in Table 1. The structural configurations which are studied include a clamped plate and a circular cylindrical shell.

\section{Clamped Plate}

The first case examined consists of a $50.8 \mathrm{~mm} \times 25.4 \mathrm{~mm} \times 5.08 \mathrm{~mm}\left[0_{8} / \mathrm{p}\right]$ plate composed of carbon/epoxy with an attached piezoceramic layer as shown in Figure 3. The plate is clamped on one side and is subjected to a uniform thermal load of $50^{\circ} \mathrm{C}$. The objective of this part of the numerical study is to verify the accuracy of the current formulation for both the sensory and active response with corresponding results from a 20 -node quadratic piezoelectric continuum element (MSC/ABAQUS, 1996), as well as a previously developed 4-node plate element (Lee and Saravanos, 1996) that implements a full layerwise laminate theory. To the author's best knowledge, the continuum element neglects pyroelectric effects in the piezoelectric formulation, so the pyroelectric constants were intentionally neglected in both the shell and plate program analysis during the comparisons with the continuum element. Subsequent studies are performed using only the plate and shell elements to investigate the influence of incorporating the pyroelectric effect. Since the three programs utilize different formulations and elements, each analysis required different finite element meshes. The shell program utilized a $10 \times 5$ mesh with two discrete layers (one for the carbon/epoxy and one for the piezoelectric). A finer 20x10 mesh was used for the 4-noded plate element with two discrete layers. The continuum element analysis incorporated a $10 \times 5 \times 2$ mesh, with the two elements through the thickness of the plate corresponding to the two discrete layers used in the shell and plate programs. All displacements $(w)$ and electric potentials $(\phi)$ presented in this section are along the centerline of the plate $(y / b=0.5)$ and are nondimensionalized using the following relationships:

$$
w^{*}=100 w / h ; \phi^{*}=\phi d_{31} 10^{5} / h
$$

where $h$ represents the plate thickness and $d_{31}$ represents the piezoelectric charge constant. 
TABLE 1: MATERIAL PROPERTIES

\begin{tabular}{|c|c|c|}
\hline & Piezoceramic & Carbon/Epoxy \\
\hline \multicolumn{3}{|c|}{ Elastic Moduli $\left(10^{9} \mathrm{~Pa}\right)$} \\
\hline $\mathrm{E}_{11}$ & 69.0 & 142.0 \\
\hline $\mathrm{E}_{22}$ & 69.0 & 10.3 \\
\hline $\mathrm{E}_{33}$ & 69.0 & 10.3 \\
\hline $\mathrm{G}_{12}$ & 26.5 & 7.20 \\
\hline $\mathrm{G}_{13}$ & 26.5 & 7.20 \\
\hline $\mathrm{G}_{23}$ & 26.5 & 4.29 \\
\hline \multicolumn{3}{|l|}{ Poisson's Ratio: } \\
\hline $\mathrm{v}_{12}$ & 0.30 & 0.27 \\
\hline$v_{13}$ & 0.30 & 0.27 \\
\hline $\mathrm{v}_{23}$ & 0.30 & 0.20 \\
\hline \multicolumn{3}{|c|}{ Thermal Expansion Coefficient $\left(10^{-6} /{ }^{\circ} \mathrm{C}\right)$ : } \\
\hline$\alpha_{11}$ & 1.20 & -0.90 \\
\hline$\alpha_{22}$ & 1.20 & 27.0 \\
\hline \multicolumn{3}{|c|}{ Piezoelectric Charge Constant $\left(10^{-12} \mathrm{~m} / \mathrm{V}\right)$ : } \\
\hline $\mathrm{d}_{31}$ & -154.0 & 0.0 \\
\hline \multicolumn{3}{|c|}{ Electric Permittivity $\left(10^{-9}\right.$ farad $\left./ \mathrm{m}\right)$ : } \\
\hline$\epsilon_{11}=\epsilon_{22}=\epsilon_{33}$ & 15.05 & 0.0266 \\
\hline \multicolumn{3}{|c|}{ Pyroelectric Constant $\left(10^{-3}\right.$ coulomb $\left./ \mathrm{m}^{2}{ }^{\circ} \mathrm{C}\right)$} \\
\hline $\mathrm{p}_{3}$ & -0.2 & 0.0 \\
\hline \multicolumn{3}{|c|}{ Reference Temperature $\left({ }^{\circ} \mathrm{C}\right)$ : } \\
\hline $\mathrm{T}_{\mathrm{o}}$ & 20.0 & 20.0 \\
\hline
\end{tabular}



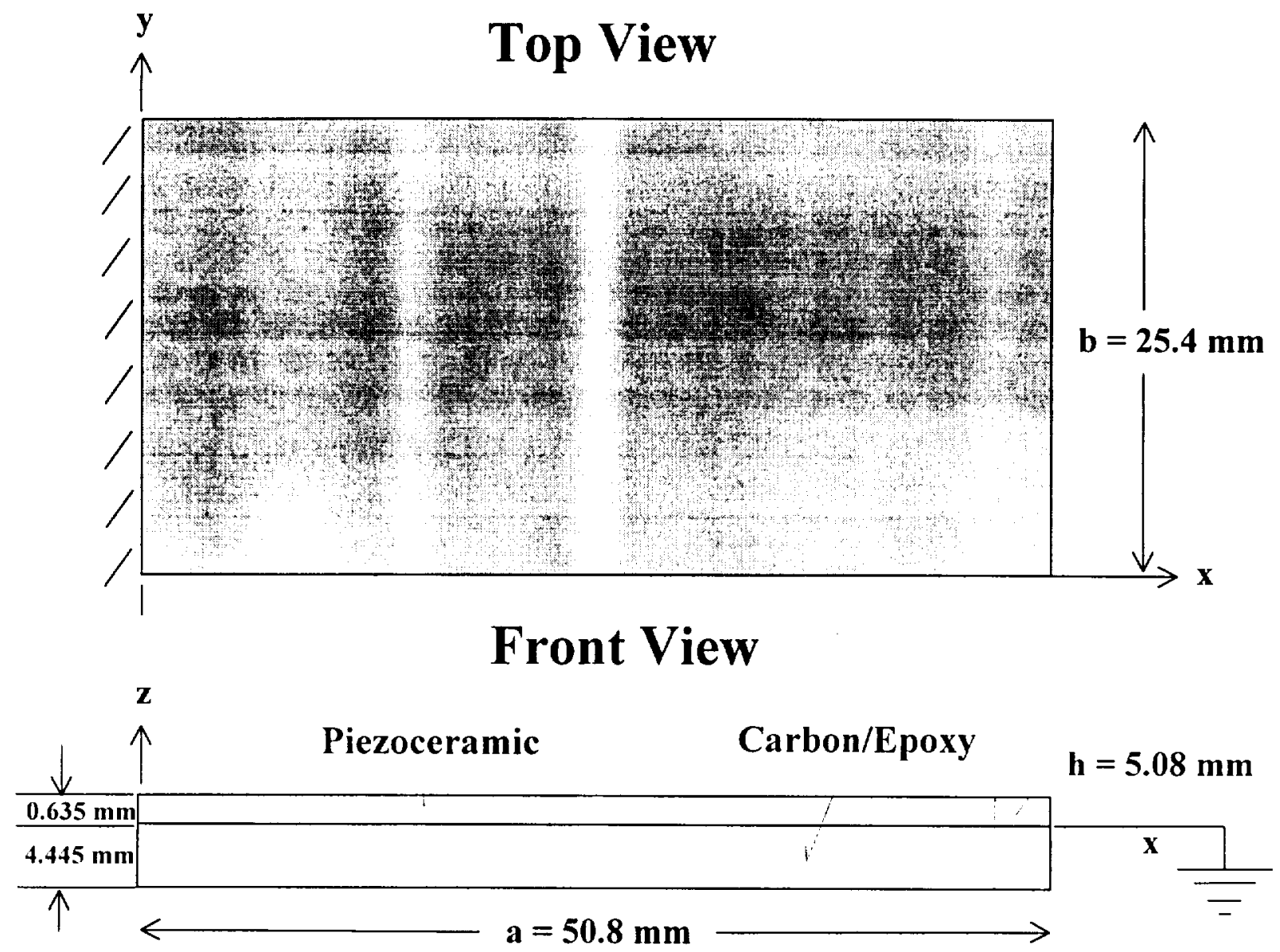

Figure 3: Geometry of a clamped plate with an attached piezoelectric layer.

Sensory Response. The response of the plate with the piezoelectric layer operating as a sensor is presented in this section. In the sensory mode, the piezoelectric layer is free to develop a corresponding electric potential in response to the thermally induced deformation of the plate through the direct piezoelectric effect. The resulting displacements predicted by the three different codes show almost exact agreement as depicted in Figure 4. The corresponding sensory electric potential which develops in the piezoelectric layer is shown in Figure 5. Although the continuum element electric potential results tend to be slightly higher due to the consideration of the through-the-thickness Poisson's effect, there is good overall agreement between the three elements.

Active Response. The piezoelectric layer can also be used as an actuator by applying a voltage differential to the piezoelectric layer and utilizing the converse piezoelectric effect to alter the thermal distortion of the plate. Figure 6 shows the centerline deflection of the plate for three different applied electric potentials $\left(\phi^{\mathrm{A}^{*}}\right)$. The three codes show almost exact agreement and demonstrate the capability to achieve thermal shape control by applying electric voltages. 


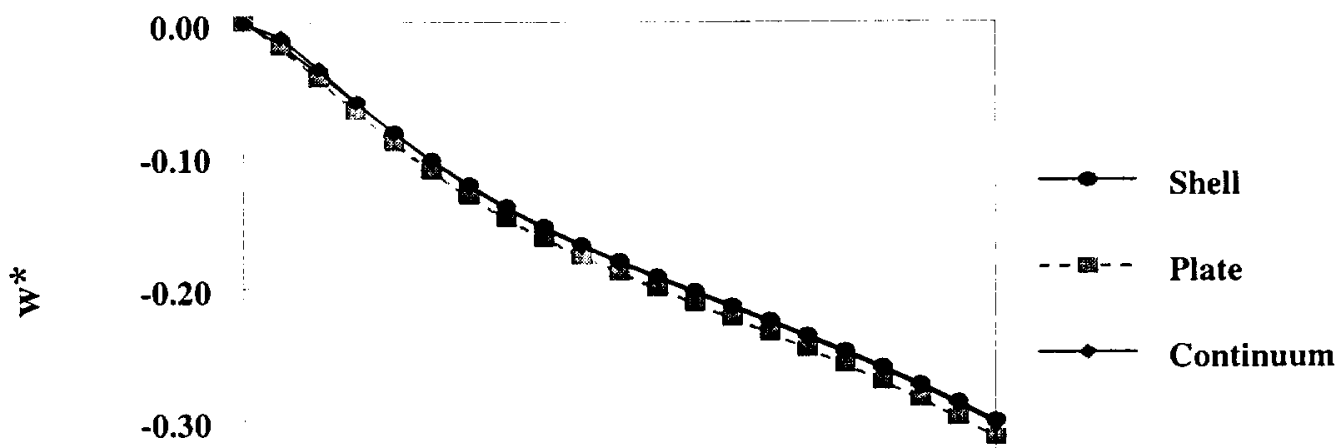

$-0.40$

\section{$\mathbf{x} / \mathbf{a}$}

Figure 4: Thermally induced sensory displacements of a $\left[0_{8} / \mathrm{p}\right]$ clamped plate.

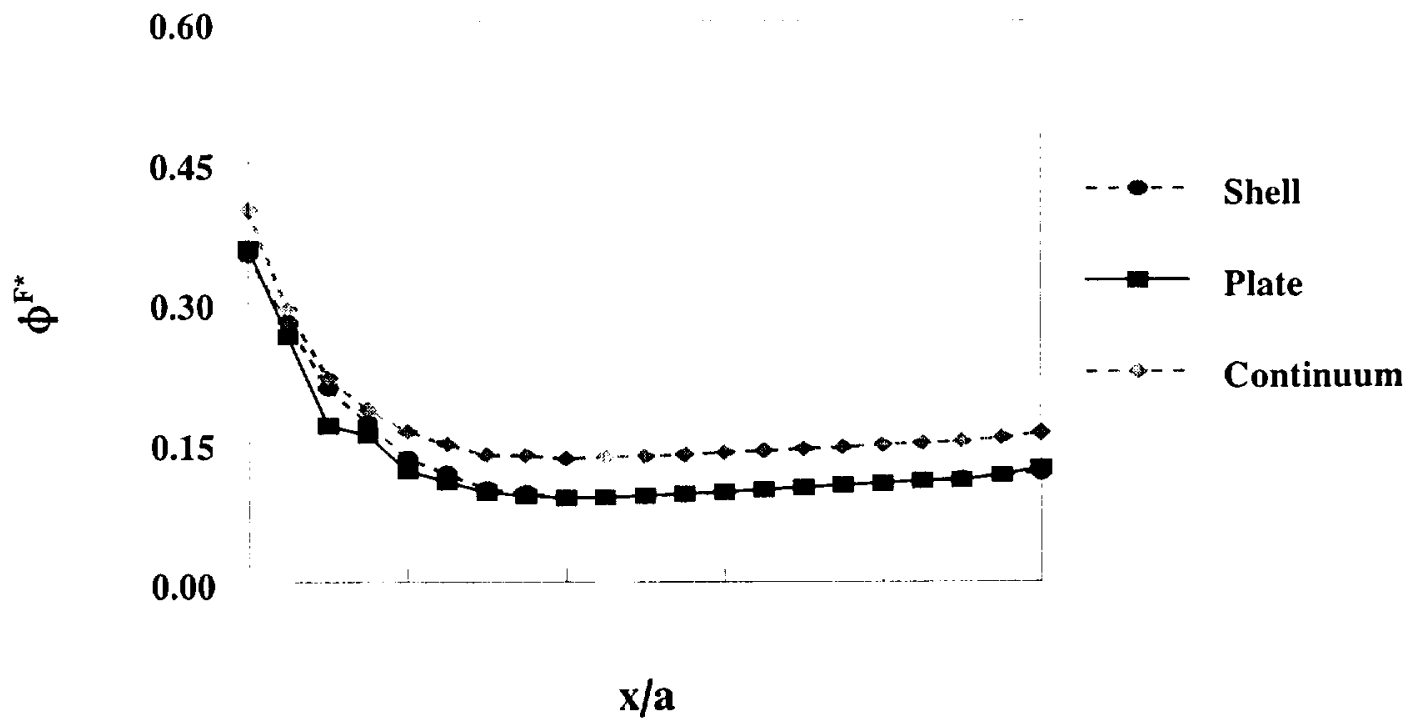

Figure 5: Thermally induced sensory electric potentials of a $\left[0_{8} / \mathrm{p}\right]$ clamped plate. 


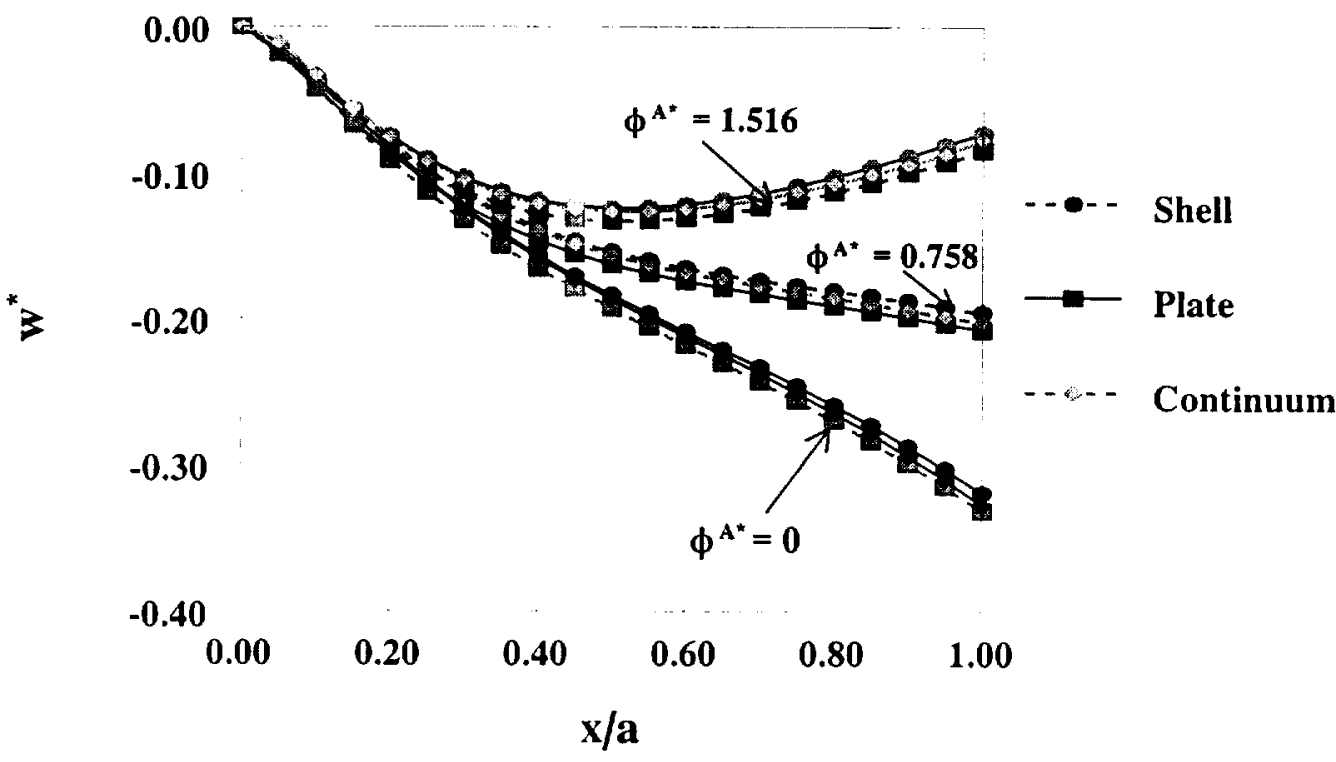

Figure 6: Displacements under active electric potentials of a $\left[0_{8} / \mathrm{p}\right]$ clamped plate.

Pyroelectric Effects. The effect of incorporating the pyroelectric constant $\left(p_{3}\right)$ into the analysis is presented in this section. The previous two cases have neglected the pyroelectric effect in order to compare with the continuum element. Results for the shell and plate elements are presented with the piezoelectric layer in a sensory mode. Figures 7 and 8 show the centerline displacements and the centerline electric potential, respectively. The case with $p_{3}=0$ represents the case without considering pyroelectric effects shown in Figures 4 and 5. Both figures show the almost exact agreement between the plate and shell elements, as well as the significant impact that pyroelectric effects can have on the displacement and electric potential of a smart structure operating in changing thermal environments. This significant influence on the structural response is caused by the coupling introduced by the piezoelectric layer and can be modeled only through coupled formulations, such as the present one. Uncoupled formulations are unable to capture this effect and can result in significant errors when modeling thermal piezoelectric structures. 


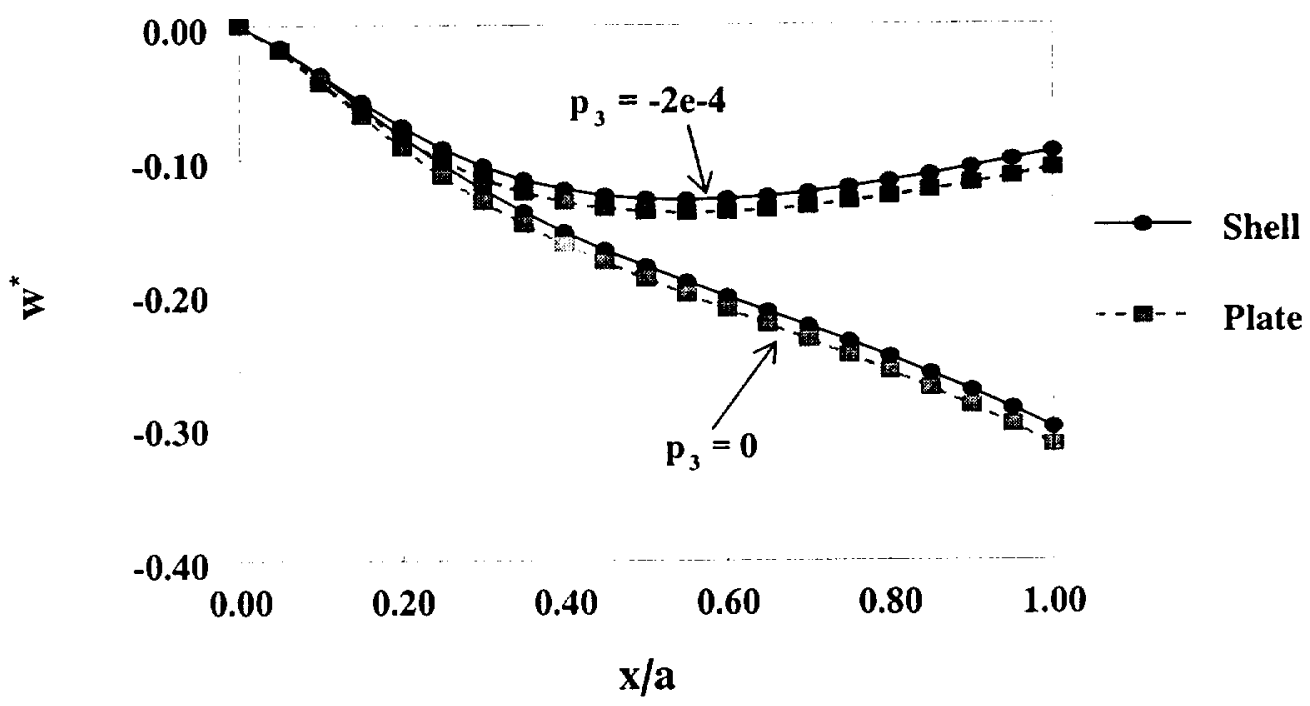

Figure 7: Pyroelectric effects on sensory displacements of a $\left[0_{8} /\right.$ p $]$ clamped plate.

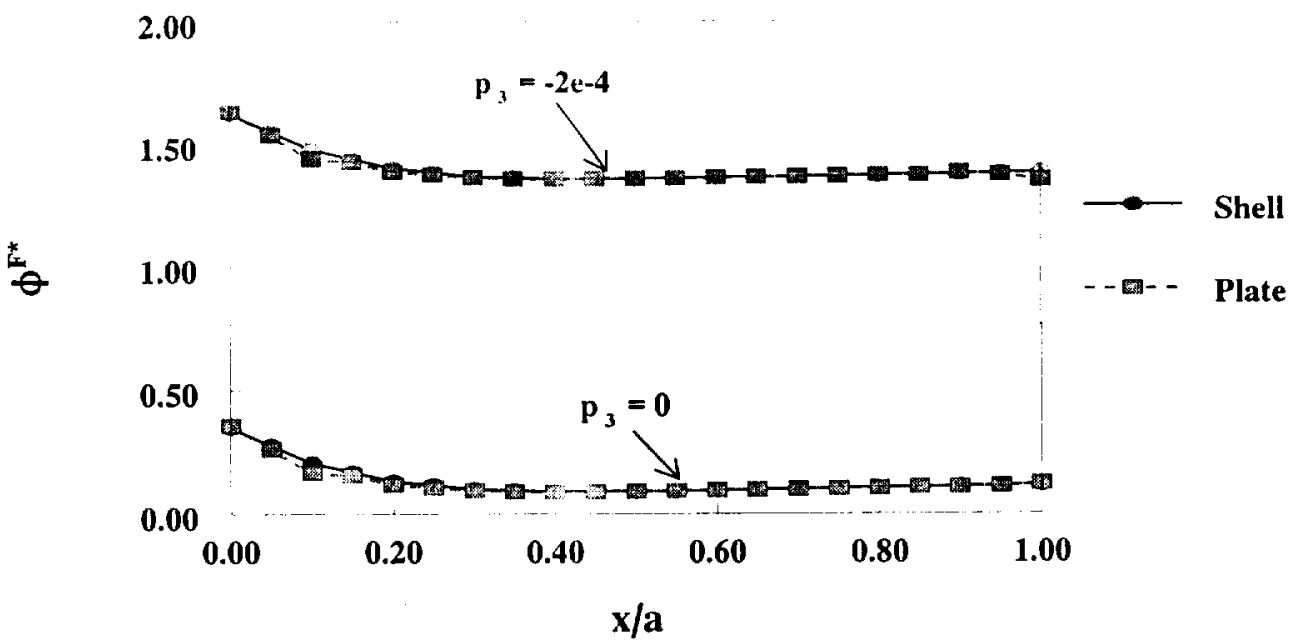

Figure 8: Pyroelectric effects on sensory electric potentials a $\left[0_{8} / \mathrm{p}\right]$ clamped plate. 


\section{Cylindrical Shell}

The second problem studied consists of a $\left[0_{9} / \mathrm{p}\right]$ (where $0^{\circ}$ is along the $\xi$ axis) circular cylinder with a radius $\mathrm{R}=0.76 \mathrm{~m}, \mathrm{a} L=1.524 \mathrm{~m}$, and a thickness $\mathrm{h}=7.62 \mathrm{~mm}$ as depicted in Figure 9. Due to the symmetry of the problem, only $1 / 8$ of the cylinder is modeled using a $10 \times 10$ mesh with two discrete layers (one for the carbon/epoxy and one for the piezoceramic). A clamped-clamped configuration in which both ends of the cylinder $(z / L=0$ and $z / L=1)$ are fixed is examined. The cylinder is subjected to three different types of thermal loads (a uniform thermal load and two types of sinusoidally varying temperatures along the hoop direction) as shown in Figure 10. Results from the current shell element are presented to investigate the influence of the curved structure on achieving thermal shape control under the different boundary conditions and applied thermal loads. All displacements $(w)$ and electric potentials $(\phi)$ presented in this section are along the hoop direction at $\mathrm{z} / \mathrm{L}=0.5$ and $\mathrm{r} / \mathrm{R}=1.0$ of the cylinder and are nondimensionalized using the following relationships:

$$
w^{\cdot}=100 w / h ; \phi^{\prime}=\phi d_{31} 10^{4} / h
$$

where $\mathrm{h}$ represents the cylinder thickness and $\mathrm{d}_{3 \mid}$ represents the piezoelectric charge constant.

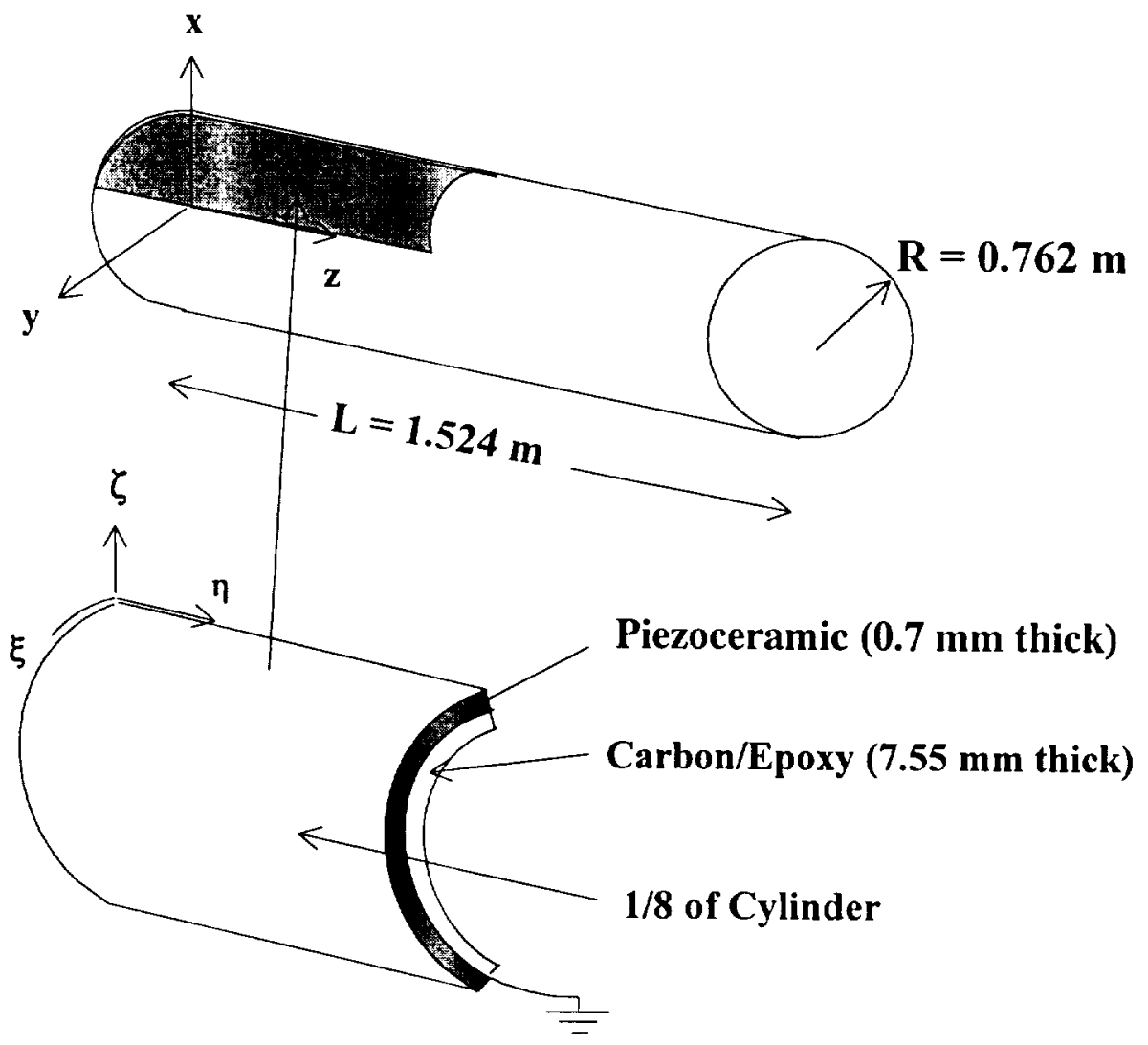

Figure 9: Geometry of a $\left[0_{8} / \mathrm{p}\right]$ circular cylinder with an attached piezoelectric layer. 


$$
\mathbf{T}=50^{\circ} \mathbf{C}
$$

(a) Uniform $\mathbf{T}$

$$
\mathbf{T}=\mathbf{5 0}^{\circ} \mathrm{C}
$$

$\gamma$

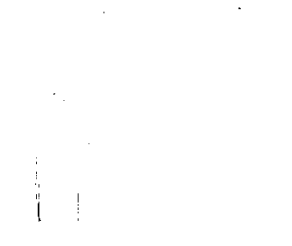

(b) $\mathrm{T} \cos \gamma$

\section{$\mathrm{T}=25^{\circ} \mathrm{C}$}

$\mathbf{Y}$

Figure 10: Different types of applied thermal loads.

Sensory Response. The sensory response of the cylinder for the three different applied thermal loads (Figure 10) are presented in Figures 11-13. Each figure contains results for the sensory displacement $\left(\mathrm{w}^{*}\right)$ and electric potential $\left(\phi^{*}\right)$ for two cases to show the effects of incorporating the pyroelectric constant in the analysis (the $p_{3}=0$ case neglects pyroelectric effects). Figure 11 shows the displacement and sensory electric potential induced from applying a uniform thermal load of $50^{\circ} \mathrm{C}$. A uniform deflection of the cylinder is achieved, which maintains the original circular shape. The sensory electric potential also shows a uniform response that corresponds to the displacement. The incorporation of pyroelectric effects produces larger displacements and electric potentials. The results from applying a cosine varying temperature are shown in Figure 12. The deflection of the cylinder now shows a sinusoidal pattern that translates into either an oval-shaped or figure eight shaped circumferential displacement, depending on whether pyroelectric effects are modeled. The electric potential only displays a sinusoidal pattern when pyroelectric effects are included and becomes almost zero when the pyroelectric effect is neglected. Figure 13 shows the results of applying a double cosine varying thermal load. A sinusoidally varying displacement and electric potential pattern is produced which corresponds to an oval-shaped deflection of the cylinder. Once again, incorporating the pyroelectric effect leads to increased displacements and electric potentials. 


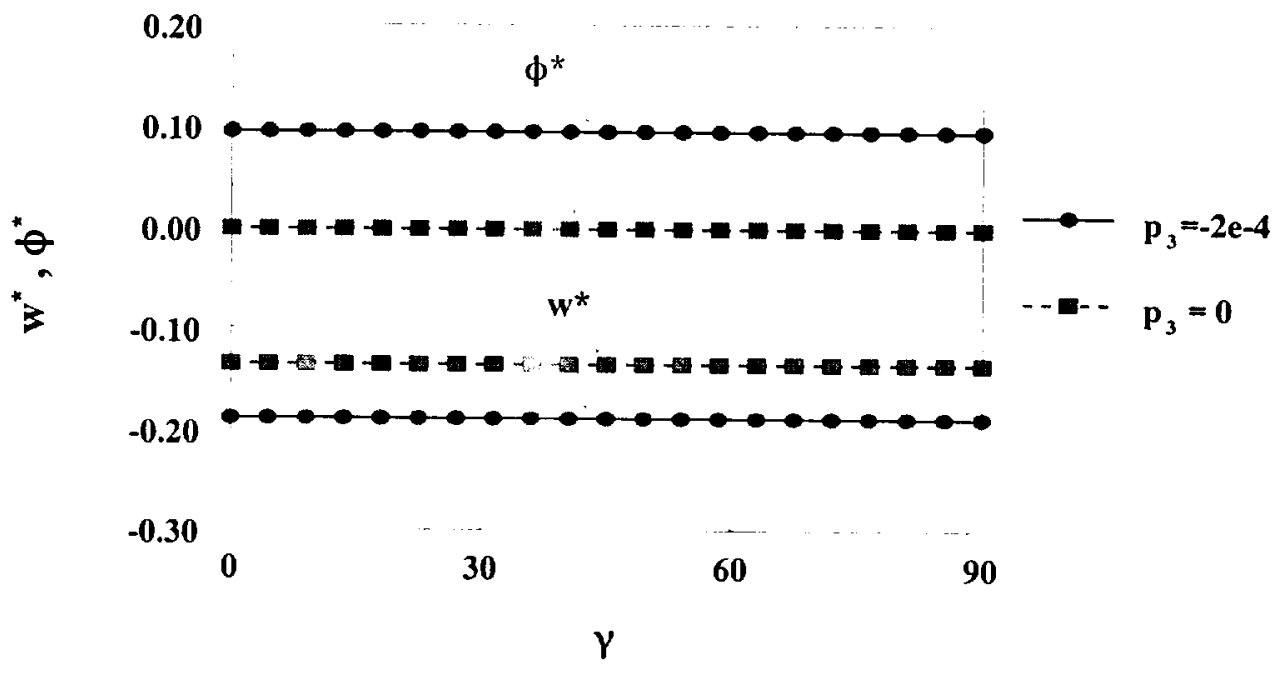

Figure 11: Sensory response of a $[0 / \mathrm{p}]$ circular cylinder under a uniform thermal load.

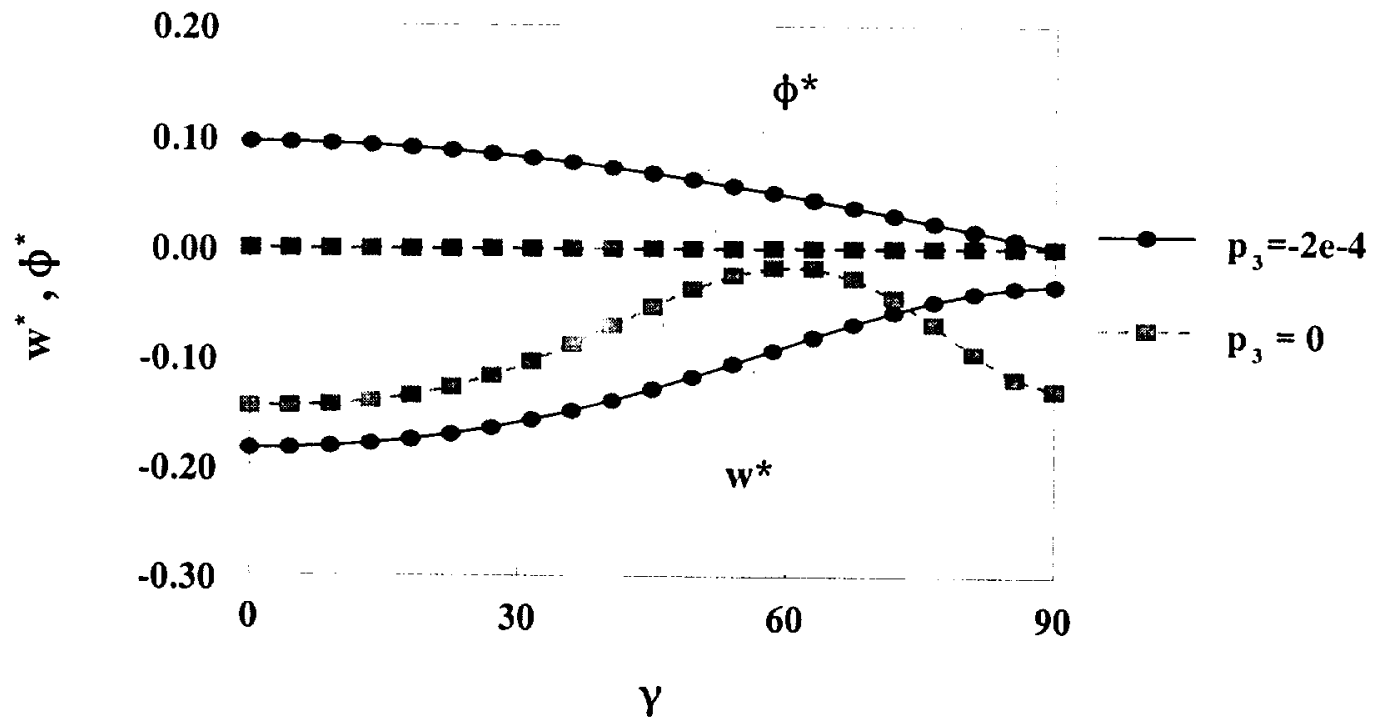

Figure 12: Sensory response of a $\left[0_{\%} / \mathrm{p}\right]$ circular cylinder under a cosine thermal load. 


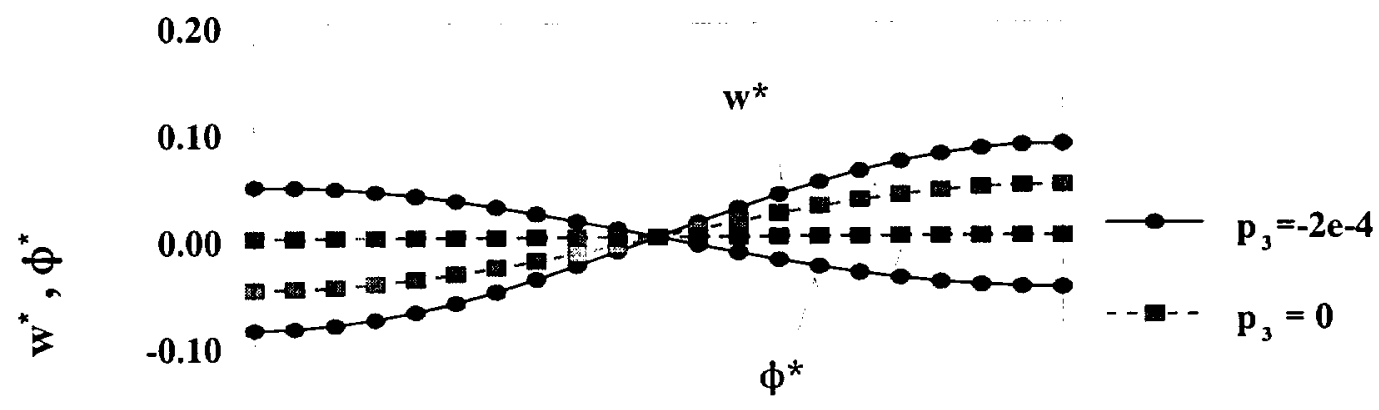

$-0.20$

$-\mathbf{0 . 3 0}$

$\begin{array}{llll}0 & 30 & 60 & 90\end{array}$

$\gamma$

Figure 13: Sensory response of a $[0 / \mathrm{p}]$ circular cylinder under a double cosine thermal load.

Active Response. The active response of the cylinder under the three applied thermal loads is examined in Figures 14-16. Each figure shows the displacement of the cylinder for three cases: the sensory thermal deflection resulting when the electric potential of the piezoelectric layer remains free, a grounded thermal configuration (zero electric potential is applied on both piezoelectric terminals), and an active thermal deflection when a non-zero electric potential is applied. The magnitude of the applied electric potential remains the same for all three cases, although the form of the electric potential varies to correspond to the type of thermal load. Figure 14 shows the deflection of the cylinder under a uniform thermal load $\left(50^{\circ} \mathrm{C}\right)$. Application of increasing uniform applied electric potentials produces a noticeable decrease in the sensory thermal deflection. Figure 15 depicts the displacement of the cylinder under a cosine varying thermal load and shows that although some changes in the overall shape of the cylinder can be obtained by applying active electric potentials, no significant overall reduction of the thermal deflection is achieved. Figure 16 illustrates the deflections produced under a double cosine variation of the thermal load. For this case, the double cosine applied electric potential effectively minimizes the thermal deflection. 
Figures 14-16 also indicate that a significant reduction in thermal deflection occurs between the sensory and grounded $\left(\phi^{\mathrm{A}}=0\right)$ configurations. This reduction is comparable to the thermal deflection achieved by applying the non-zero electric potentials and is attributed to the influence of pyroelectric effects on the response of the cylinder. The modeling of this effect is a direct consequence of the coupled formulation. Under thermal loads, the pyroelectric effect has a significant impact on the sensory electric potential, $\phi^{F}$, in Eq. (22). Incorporating this increased sensory electric potential into the structural displacements, Eq. (23), produces a corresponding effect on the deflections. However, when the piezoelectric material is in an active configuration, the sensory electric potentials are eliminated, significantly reducing the pyroelectric effect on the displacements as shown in Figures 14-16. While these results help illustrate the advantages of the current coupled formulation, it also shows a potential drawback of using piezoceramics as sensors in high temperature applications. Although typical piezoceramics have higher use temperatures than piezopolymers, the pyroelectric effect can lead to significant changes in the mechanical state of the structure and appropriate design considerations will be required for effective operations in thermal environments.

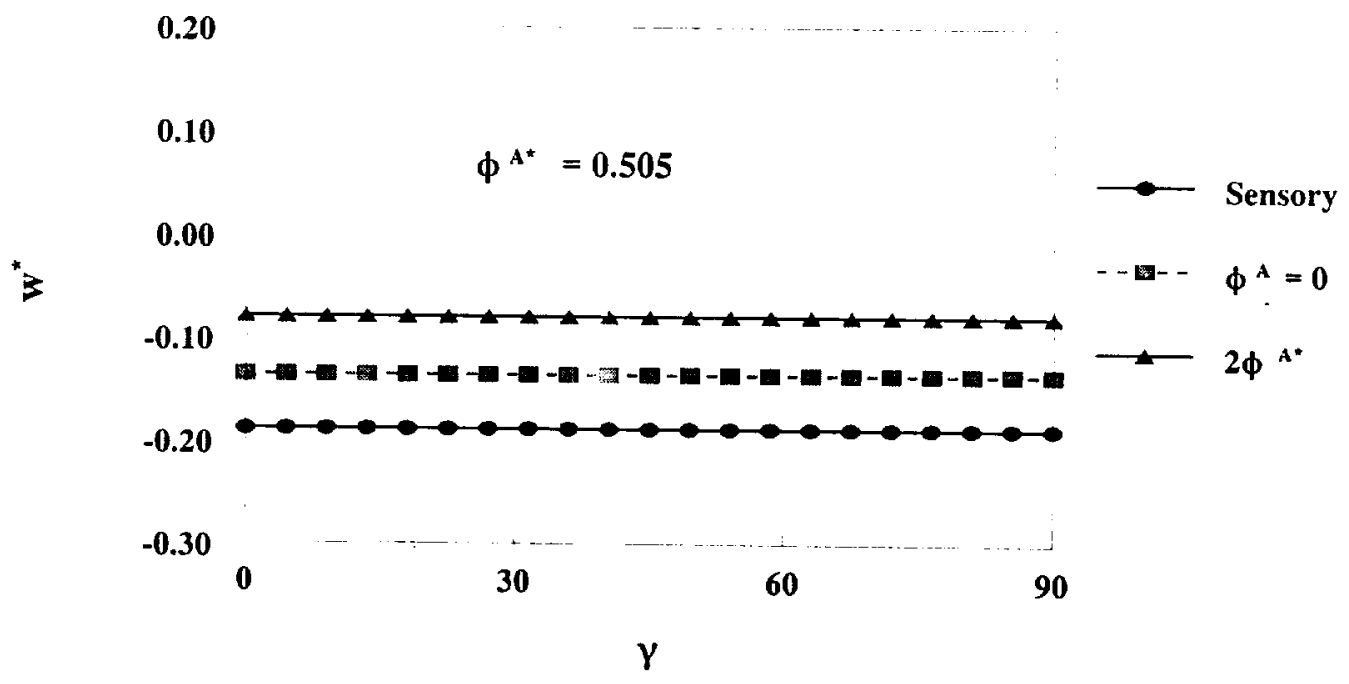

Figure 14: Displacements of a $[0 / p]$ circular cylinder under a uniform thermal load. 


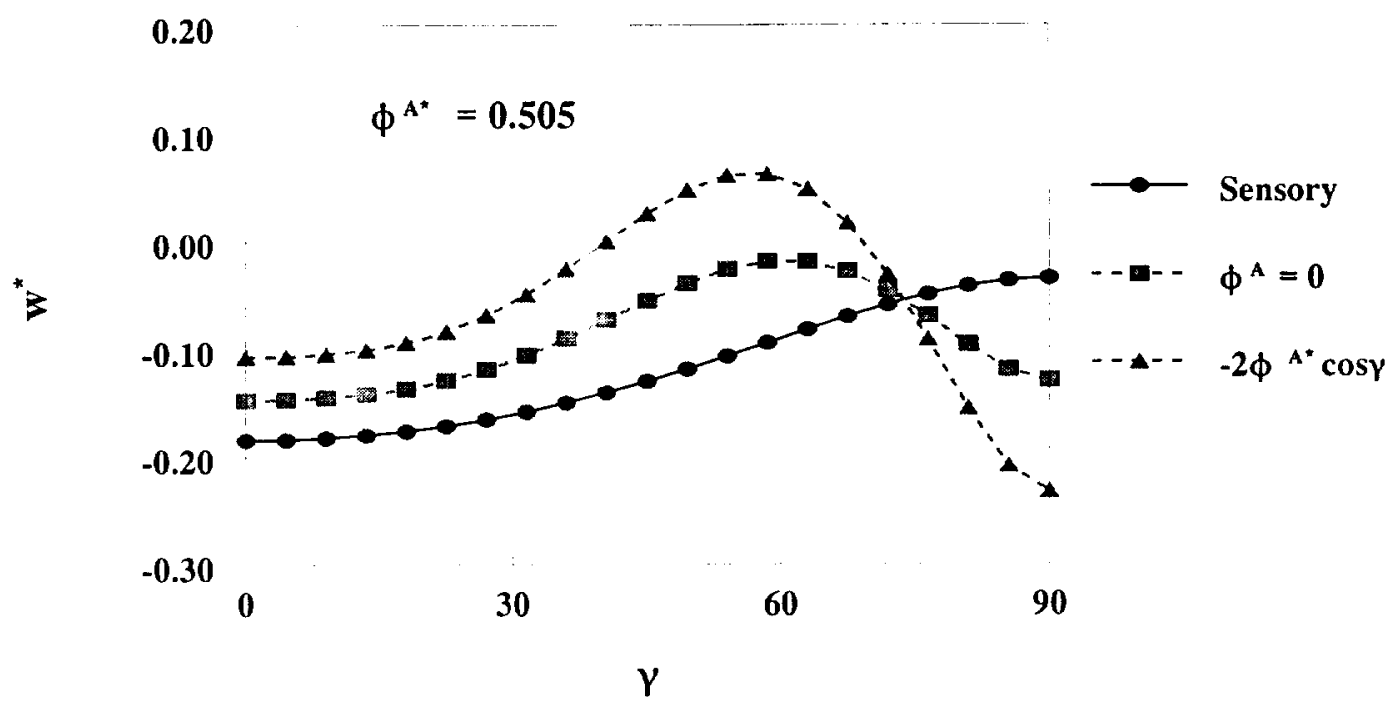

Figure 15: Displacements of a $\left[0_{9} / \mathrm{p}\right]$ circular cylinder under a cosine thermal load.

\subsection{0}

0.10

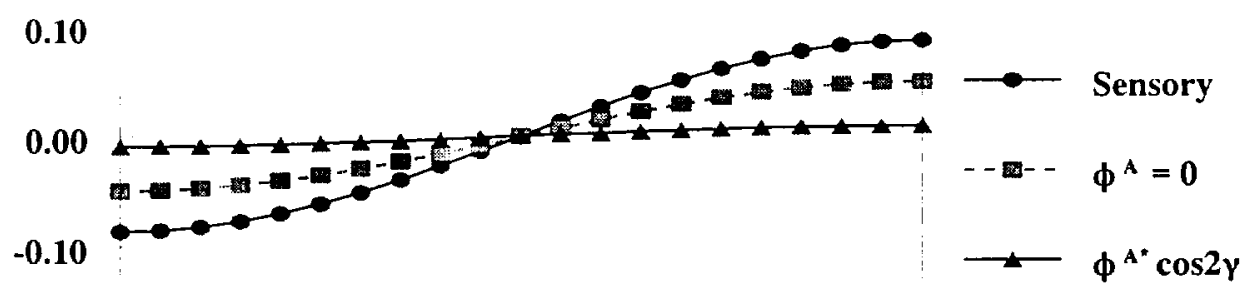

$-0.20 \quad \phi^{A^{*}}=0.505$

$-0.30$

$\mathbf{0} \quad 30$

60

90

$\gamma$

Figure 16: Displacements of a $\left[0_{9} / \mathrm{p}\right]$ circular cylinder under a double cosine thermal load. 


\section{SUMMARY}

A multi-field laminate theory and mechanics to model the coupled mechanical, electrical, and thermal behavior of piezoelectric composite shells were described. The corresponding equations of motion were developed in curvilinear coordinates and implemented into a quadratic shell element. Analytical studies were conducted to compare the accuracy of the current formulation with a commercial finite element code, as well as with a previously developed formulation. Additional numerical studies have shown the significant impact of piezoelectric coupling and pyroelectric effects on the sensory response of thermal piezoelectric structures. The response of cylindrical shells under combinations of applied thermal and electric loadings was quantified and numerical examples illustrate the feasibility of active thermal shape control on curved structures. 


\section{REFERENCES}

K. Chandrashekhara and M. Kolli (1995). Thermally Induced Vibration of Adaptive Doubly Curved Composite Shells with Piezoelectric Devices. AIAA-95-1352-CP, Proceedings of the 36th AIAA/ASME/ASCE/AHS/ASC Structures, Structural Dynamics and Materials Conference, Apr 1013, New Orleans, LA, pp. 1628-1629.

J.S. Choi, H.F. Ashida and N. Noda (1997). Control of Thermally Induced Elastic Displacement of an Isotropic Structural Plate bonded to a Piezoelectric Ceramic Plate. Acta Mechanica, 122, 49-63.

E.F. Crawley (1994). Intelligent Structures for Aerospace: A Technology Overview and Assessment. AIAA Journal, 32:8, 1689-1699.

C.M. Docmeci (1990). Shell Theory for Vibrations in Piezoceramics under a Bias. IEEE Transcactions on Ultrasonics, Ferroelectrics, and Frequency Control, 37:5, 369-385.

G.P. Dube, S. Kapuria and P.C. Dumir (1996a). Exact Piezothermoelastic Solution of SimplySupported Orthotropic Circular Cylindrical Panel in Cylindrical Bending. Archive of Applied Mechanics, 66, 537-554.

G.P. Dube, S. Kapuria and P.C. Dumir (1996b). Exact Piezothermoelastic Solution of SimplySupported Orthotropic Flat-Panel in Cylindrical Bending. International Journal of Mechanical Sciences, 38:11, 1161-1177.

P. Heyliger, K.C. Pei and D.A. Saravanos (1996). Layerwise Mechanics and Finite Element Model for Laminated Piezoelectric Shells. AIAA Journal, 34:11, 2353-2360.

R. Lammering (1991). The Application of a Finite Shell Element for Composites Containing Piezoelectric Polymers in Vibration Control. Computers and Structures, 41:5, 1101-1109.

H.-J. Lee and D.A. Saravanos (1996). Coupled Layerwise Analysis of Thermopiezoelectric Composite Beams. AIAA Journal, 34:6, 1231-1237.

H.-J. Lee and D.A. Saravanos (1997). Generalized Finite Element Formulation for Smart Multilayered Thermal Piezoelectric Composite Plates. International Journal of Solids and Structures, 34:26, 3355-3371.

MSC/ABAQUS (1996). MSC/ABAQUS User's Manual Version 5.6, Volumes I-III. MacNealSchwendler Corporation, Los Angeles.

J.F. Nye (1964). Physical Properties of Crystals. The Clarendon Press, Oxford.

S.S. Rao and M. Sunar (1993). Analysis of Distributed Thermopiezoelectric Sensors and Actuators in Advanced Intelligent Structures. AIAA Jouınal, 31:7, 1280-1286. 
S.S. Rao and M. Sunar (1994). Piezoelectricity and Its Use in Disturbance Sensing and Control of Flexible Structures: A Survey. Applied Mechanics Review, 47:4, 113-123

C.A. Rogers (1993). Intelligent Material Systems - The Dawn of a New Materials Age. Journal of Intelligent Material Systems and Structures, 4, 4-12.

D.A. Saravanos (1997). Coupled Mixed-Field Laminate Theory and Finite Element for Smart Piezoelectric Composite Shell Structures. AIAA Journal, 35:8, 1327-1333.

D.A. Saravanos and P.R. Heyliger (1998). Mechanics and Computational Models for Laminated Piezoelectric Beams, Plates, and Shells. Applied Mechanics Reviews (in review).

T.R. Tauchert (1992). Piezothermoelastic Behavior of a Laminated Plate. Journal of Thermal Stresses, 15, 25-37.

H.S. Tzou and Y. Bao (1995). Theory on Anisotropic Piezothermoelastic Shell Laminates with Sensor/Actuator Applications. Journal of Sound and Vibration, 184:3, 453-473.

H.S. Tzou and Y. Bao (1997). Nonlinear Piezothermoelasticity and Multi-Field Actuations, Part 1: Nonlinear Anisotropic Piezothermoelastic Shell Laminates. Journal of Vibration and Acoustics, 119. 374-381.

H.S. Tzou and M. Gadre (1989). Theoretical Analysis of a Multi-Layered Thin Shell Coupled with Piezoelectric Shell Actuators for Distributed Vibration Controls. Journal of Sound and Vibration 132:3, 433-450.

H.S. Tzou and R.V. Howard (1994). A Piezothermoelastic Thin Shell Theory Applied to Active Structures. Journal of Vibration and Acoustics, 116, 295-302.

H.S. Tzou and R. Ye (1994). Piezothermoelasticity and Precision Control of Piezoelectric Systems: Theory and Finite Element Analysis. Journal of Vibration and Acoustics, 116, 489-495.

H.S. Tzou and R. Ye (1996). Analysis of Piezoelastic Structures with Laminated Piezoelectric Triangle Shell Elements. AIAA Journal, 34, 110-115.

K.M. Xu and A.K. Noor (1996). 3-Dimensional Analytical Solutions for Coupled Thermoelectroelastic Response of Multilayered Cylindrical-Shells AIAA Journal, 34:4, 802-812.

K.M. Xu, A.K. Noor and Y.Y. Tang (1997). 3-Dimensional Solutions for Coupled Thermoelectroelastic Response of Multilayered Plates. Computer Methods in Applied Mechanics and Engineering, 126, 355-371. 



\begin{tabular}{|c|c|c|c|}
\hline \multicolumn{3}{|c|}{ REPORT DOCUMENTATION PAGE } & $\begin{array}{l}\text { Form Approved } \\
\text { OMB No. } 0704-0188\end{array}$ \\
\hline \multicolumn{4}{|c|}{ 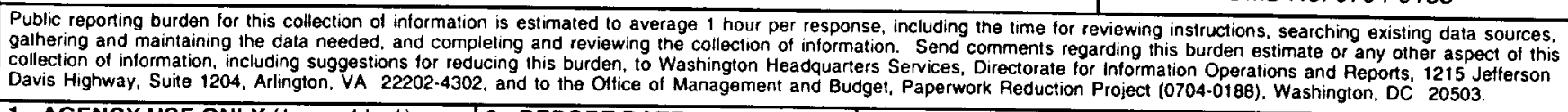 } \\
\hline 1. AGENCY USE ONLY (Leave blank) & 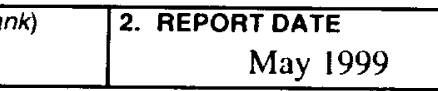 & \begin{tabular}{|r|r|} 
3. REPORT TYPE AND \\
Tecl \\
\end{tabular} & $\begin{array}{l}\text { DATES COVERED } \\
\text { chnical Memorandum }\end{array}$ \\
\hline \multicolumn{3}{|c|}{$\begin{array}{l}\text { 4. TITLE AND SUBTITLE } \\
\text { A Mixed Multi-Field Finite Element Formulation for Thermopiezoelectric } \\
\text { Composite Shells }\end{array}$} & \multirow{2}{*}{$\begin{array}{l}\text { 5. FUNDING NUMBERS } \\
\text { WU-523-21-13-00 }\end{array}$} \\
\hline $\begin{array}{l}\text { 6. AUTHOR(S) } \\
\text { Ho-Jun Lee and Dimitris }\end{array}$ & A. Saravanos & & \\
\hline \multicolumn{3}{|c|}{$\begin{array}{l}\text { 7. PERFORMING ORGANIZATION NAME(S) AND ADDAESS(ES) } \\
\text { National Aeronautics and Space Administration } \\
\text { John H. Glenn Research Center at Lewis Field } \\
\text { Cleveland, Ohio } 44135-3191\end{array}$} & $\begin{array}{l}\text { 8. PERFORMING ORGANIZATION } \\
\text { REPORT NUMBER } \\
\text { E-11690 }\end{array}$ \\
\hline \multicolumn{3}{|c|}{$\begin{array}{l}\text { 9. SPONSORING/MONITORING AGENCY NAME(S) AND ADDRESS(ES) } \\
\text { National Aeronautics and Space Administration } \\
\text { Washington, DC 20546-0001 }\end{array}$} & $\begin{array}{l}\text { 10. SPONSORING/MONITOAING } \\
\text { AGENCY REPORT NUMBER } \\
\text { NASA TM-1999-209181 }\end{array}$ \\
\hline \multicolumn{4}{|c|}{$\begin{array}{l}\text { 11. SUPPLEMENTARY NOTES } \\
\text { Prepared for the 6th Annual International Symposium on Smart Structures and Materials sponsored by the International } \\
\text { Society for Optical Engineering. Newport Beach, California, March 1-5, 1999. Ho-Jun Lee, NASA Glenn Research } \\
\text { Center; and Dimitris A. Saravanos, Ohio Aerospace Institute, 22800 Cedar Point Road, Cleveland, Ohio } 44142 \text {. Respon- } \\
\text { sible person, Ho-Jun Lee, organization code 5930, (216) 433-3316. }\end{array}$} \\
\hline \multicolumn{3}{|c|}{ 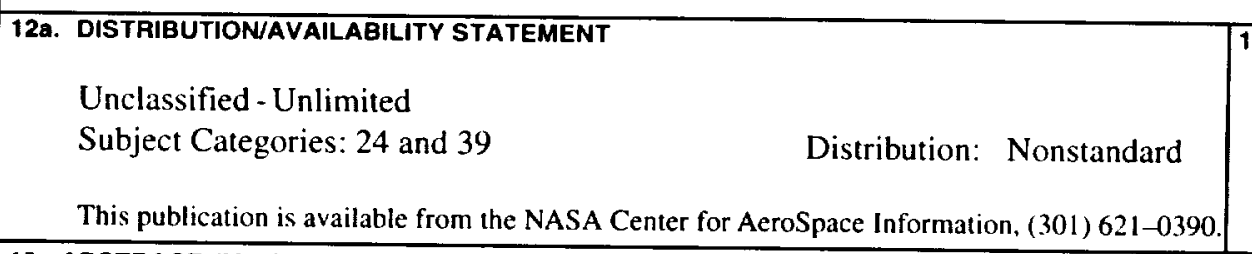 } & 12b. DISTRIBUTION CODE \\
\hline \multicolumn{4}{|c|}{$\begin{array}{l}\text { 13. ABSTRACT (Maxlmum } 200 \text { words) } \\
\text { Analytical formulations are presented which account for the coupled mechanical, electrical, and thermal response of } \\
\text { piezoelectric composite shell structures. A new mixed multi-field laminate theory is developed which combines "single } \\
\text { layer" assumptions for the displacements along with layerwise fields for the electric potential and temperature. This } \\
\text { laminate theory is formulated using curvilinear coordinates and is based on the principles of linear thermopiezoelectricity. } \\
\text { The mechanics have the inherent capability to explicitly model both the active and sensory responses of piezoelectric } \\
\text { composite shells in thermal environment. Finite element equations are derived and implemented for an eight-noded shell } \\
\text { element. Numerical studies are conducted to investigate both the sensory and active responses of piezoelectric composite } \\
\text { shell structures subjected to thermal loads. Results for a cantilevered plate with an attached piezoelectric layer are com- } \\
\text { pared with corresponding results from a commercial finite element code and a previously developed program. Additional } \\
\text { studies are conducted on a cylindrical shell with an attached piezoelectric layer to demonstrate capabilities to achieve } \\
\text { thermal shape control on curved piezoelectric structures. }\end{array}$} \\
\hline \multirow{2}{*}{\multicolumn{3}{|c|}{$\begin{array}{l}\text { 14. SUBJECT TERMS } \\
\text { Composite; Piezoelectric; Temperature; Shells: Adaptive structure; Smart materials; } \\
\text { Sensors; Actuators; Finite element method }\end{array}$}} & $\begin{array}{c}\text { 15. NUMBER OF PAGES } \\
30 \\
\end{array}$ \\
\hline & & & 16. PRICE CODE \\
\hline $\begin{array}{l}\text { 17. SECURITY CLASSIFICATION } \\
\text { OF REPORT } \\
\text { Unclassified }\end{array}$ & $\begin{array}{l}\text { 18. SECURITY CLASSIFICATION } \\
\text { OF THIS PAGE } \\
\text { Unclassified }\end{array}$ & $\begin{array}{l}\text { 19. SECURITY CLASSIFICATIOI } \\
\text { OF ABSTRACT } \\
\text { Unclassified }\end{array}$ & $\begin{array}{l}\text { A03 } \\
\text { 20. LIMITATION OF ABSTRACT }\end{array}$ \\
\hline
\end{tabular}

